\title{
Challenges Encountered in the Implementation of Online Distance Learning
}

\author{
Analyn S. Clarin* \& Esther L. Baluyos \\ Misamis University, Ozamiz City, 7200,Philippines
}

\begin{abstract}
Teachers face several drawbacks and potential issues while participating in an online class. This study explored the challenges encountered by teachers in implementing online distance learning in the Basic Education Department, specifically in the Junior and Senior High School, of Misamis University, Ozamiz City. The study utilized a qualitative approach using phenomenological design. The study included twenty (20) participants from the teachers handling online classes in the Junior and Senior High Schools, selected through purposive sampling. In-depth face-to-face interviews were used in gathering information from the teachers. The researcher employed the seven steps of Colaizzi's method of data analysis. Results revealed the following themes: (1) the need to motivate the students in learning the lessons; (2) the preparation of learning resources; (3) poor internet connection; and (4) constant communication with students and parents. Teachers may integrate activities that would keep the students engaged throughout the lesson. Back-up plans may be designed to address the challenge of internet connectivity which interfere the teaching-learning process.
\end{abstract}

Keywords: communication, engagement, internet connection, learning resources, online distance learning

\section{Introduction}

Online learning is rapidly penetrating school districts across the country (Gilbert, 2015). Advanced technologies, such as Internet technology, allow for online learning to be held to enhance instructors' roles in supporting learning and shifting of teacher duties (Muhtia, Suparno, \& Sumardi, 2018). Researchers and educators must assess the effectiveness of online learning compared to traditional face-to-face learning and the elements that influence online course effectiveness (Nguyen, 2015).

Blended learning is a popular term for a method that combines the advantages of both face-to-face and online learning. However, this strategy of mixing online and face-to-face educational components has created concerns (Rasheed, Kaman sin, \& Abdullah, 2020). Planning difficulties, such as negotiating task understandings and goals, can significantly impact students' regulation and task performance (Hadwin, Bakhtiar \& Miller, 2018).

In many areas, including activities, assignments, evaluations, objectives, student quality, and means of addressing academic dishonesty, online courses that are purposefully and carefully constructed are equivalent to face-to-face courses. However, there are disparities in the quality and quantity of engagement as well as skill development. Students are required to interact with the subject and with each other in ways that are possibly more demanding and engaging than face-to-face courses. Quality assurance methods are being investigated, including intense insta rector presence, real-time online meetings, and well-formulated discussion questions that require students to interact with the content and each other in ways that are potentially more challenging and engaging than face-to-face courses. Further challenges of technology, class size, and requirement of additional faculty time are discussed, and clinical content that is presently more suitably taught with a face-to-face component (Jones, 2015).

There is no single description that encompasses all assets of online learning environments is crucial to understanding online learning. While taking an online course, students may encounter several disadvantages and potential concerns.

\footnotetext{
* Corresponding author.

E-mail address: analynsclarin@gmail.com (Analyn S. Clarin)
} 
Academic rigor is a subject that is frequently questioned. When assessing the academic rigor (or lack thereof) of an online course, it's crucial to consider the many different formats in which online education can be given, the wide range of subjects that online courses can teach, and the ever-growing student population. Another problem that online students confront is keeping their motivation in an online course. Overall, students who lacked independence and selfmotivation had lower success rates than their counterparts (Gilbert, 2015).

A comprehensive evaluation of literature was done to identify the obstacles in the online component of blended learning. The main challenges that students confront are self-regulation issues and difficulties with learning technologies. The majority of the issues that teachers face are related to the usage of technology in the classroom. Educational institutions face key issues in providing appropriate instructional technology and adequate teacher training support (Rasheed, Kamsin, \& Abdullah, 2020).

The coronavirus disease 2019 (COVID-19) pandemic has significantly influenced all parts of our life, including education and the economy. Stay-at-home orders have been issued by governments around the world, resulting in the closure of institutions. As a result, online classes have become an important part of maintaining educational continuity (Rajab, Gazal, \& Alkattan, 2020). Many students access online resources using their mobile devices, substituting this for traditional learning interactions (Anshari, Alas, Sabtu, \& Hamid, 2016).

A study from Saudi Arabia investigated the influence of the COVID-19 epidemic on online education. Communication, student assessment, usage of technology tools, online experience, pandemic-related worry or stress, time management, and technophobia were among the cited barriers to online education during the COVID-19 pandemic. (Rajab, Gazal, \& Alkattan, 2020). Participation barriers are especially noticeable in group work activities. Many academic staff members have challenges in the online world since they are increasingly required to have higher levels of technology awareness and expertise in addition to their regular academic responsibilities. Workplace anxiety or stress, time management, and technophobia are all factors to consider. (Gillett-Swan, 2017).

Another study uncovered obstacles in Virtual Learning Environments (VLEs), notably those connected to participative difficulties, which are increasingly acknowledged in educational studies from a sociocultural perspective as the essence of successful learning in any subject. Learners' proactive and critical engagement in knowledge production through online social interaction, as opposed to passive absorption, has high stakes directly related to effective programs and their desired outcomes (Charbonneau-Gowdy, 2018). Furthermore, a study organizes and summarizes the findings and obstacles of online learning into positive, negative, mixed, and null findings to analyze the evidence of its usefulness. Meta-analyses of the efficacy of online learning, the heterogeneous consequences of student learning, and the endogenous issue of learning environment choice are all given special consideration. Overall, there is strong evidence to demonstrate that online learning is as effective as traditional learning (Nguyen, 2015).

A study in Brunei Darussalam looked at current Internet activity and literacy with citizens' Internet activity and online learning. The study focused on online learning and its potential in the big data era, highlighting milestones in recent difficulties, and trends in Internet activity. According to the survey, Brunei expect improved learning services and experiences through an online learning system to promote literacy and the quality and efficiency of learning, according to the survey (Anshari, Alas, Sabtu, \& Hamid, 2016). In addition, research looked into the obstacles to elearning deployment in Kenyan public universities. The findings showed that e-learning has some problems Kenyan public institutions must resolve before implementing it successfully. The advantages and opportunities offered by elearning, on the other hand, considerably outweighted the drawbacks (Tarus, Gichoya, \& Muumbo, 2015).

Researches in the Philippines looked at teachers' awareness of the COVID-19 pandemic, their thoughts on their schools' preparedness, and their reactions to the problems of conducting distance learning education. The findings suggested that the teachers were well aware of the COVID-19 pandemic's presence and repercussions (Alea, Fabrea, Roldan, \& Farooqi, 2020). Despite the COVID-19 difficulties, educational countermeasures were done to ensure that kids continue to receive an education (Toquero, 2020). The new normal should be considered in formulating and implementing the "new normal educational policy" to maintain and provide quality education despite lockdown and community quarantine (Tria, 2020).

In Misamis University, the teachers are faced with the complexities in preparing learning materials for online learning in order to achieve its mission of providing quality education to students despite the lockdowns brought about by the pandemic COVID-19. The teachers encountered a lot of challenges in the implementation of online distance learning 


\subsection{Objective of the Study}

This study explored the challenges encountered by teachers in the implementation of online distance learning in the Basic Education Department of Misamis University, Ozamiz City.

\section{Research Methods}

\subsection{Research Design}

This study utilized a qualitative approach using phenomenological design with Collaizzi's method of data analysis. Basically, the phenomenological approach is the assumption that human experience is mediated through interpretation (Creswell, 2009); consequently, the core of the phenomenological approach is the investment in other people's experiences and the meaning they make of those experiences (Seidman, 1998). This approach was used exploring the challenges encountered by teachers in the implementation of online distance learning.

\subsection{Research Setting}

The research was conducted in the Basic Education Department, especially in the Junior and Senior High School, of Misamis University, Ozamiz City. It is a privately owned, non-sectarian educational institution founded by Dr. Hilarion Feliciano and Doña Maria Mercado Feliciano in 1929. The university, is an ISO 9001:2015 Management System Certified granted by Det Norske Veritas-Germanischer Lloyd Business Assurance. The university is also granted Autonomous Status by the Commission on Higher Education (CHED). The Basic Education Department is granted Level II accreditation by the Philippine Association of Colleges and Universities Commission on Accreditation (PACUCOA).

\subsection{Participants of the Study}

The study participants were the twenty Junior and Senior high school teachers in the Basic Education Department of Misamis University, Ozamiz City. The participants were chosen through purposive sampling using the criteria of: 1) handling at least the basic load; 2) no previous experience in handling online classes; and 3) willing to participate in the study.

\subsection{Research Instrumentation}

The interview guide question (Appendix C) was used for the conduct of in-depth interviews. The participants were interviewed about the challenges they encountered in handling online classes. In this study, the interview guide was developed by the researcher. Experts on qualitative research were asked to do the content validity test to develop the interview guide questions. Approval from the dissertation committee was secured by the researcher prior to the conduct of the interview. Interview questions were piloted before the study was conducted to check for clarity and to ensure they would elicit the information in response to the research questions.

\subsection{Data Collection}

Before the conduct of the study, the researcher obtained permission from the Misamis University Graduate School office and the Associate Principals of the Junior and Senior High School of the Basic Education Department for the conduct of the research. Upon the approval of the letter requests, the researcher conducted the interview using the structured interview guide to obtain the data on the challenges encountered in online classes from the participants. The researcher interviewed the participants at a pre-agreed time and schedule for 40 minutes each. The participants were assured of the confidentiality of the data, and it was explained that they might withdraw anytime within the conduct of the study. 
The participants were asked to fill out an informed consent form. The interview started by identifying the participants and reviewing the purpose of the interview. A face-to-face interview was used to clarify questions. In the conduct of the face-to-face interview, the researcher ensured that safety measures and protocols set by the COVID-19 InterAgency Task Force (IATF) were followed. The researcher took down notes during the interview, and a digital recorder was used for the researcher to review what transpired during the interview. The recorded interviews were transcribed and the researcher's reflective notes of her observations of the interviews were collected and added to the interview data. The participants were then asked to review the drafts of the written report of the study to have additional feedback to establish accuracy.

\subsection{Ethical Considerations}

To adhere to ethical standards, the researcher used the Helsinki Declaration (2001) codes. The researcher informed all participants about the study's objectives and significance. The principle of autonomy and respect for the person was upheld through the process of informed consent. The participants' written, informed consent was obtained before the interview. The participants were informed of the aim of the study; potential benefits to themselves or others; confidentiality protection; researcher's contact information for answers to questions regarding the study; and conditions of participation, including the right to refuse or withdraw at any time without penalty. The researcher assured the participants that their participation was entirely voluntary, and they have the right to decline to participate at any time during the conduct of the interview.

\subsection{Data Analysis}

To come up with the findings, the researcher followed the seven-step method of data analysis of Colaizzi (1978), the seven - steps are: 1.) making sense or acquiring a feeling for the protocol, 2.) extracting significant statements, 3.) formulating meanings, 4.) organizing the cluster themes, $5 \& 6$.) integration of results and detailed description, and 7.) validation.

\subsection{Colaizzi’s Seven-Step Method of Data Analysis}

\subsubsection{Making sense or acquiring a feeling for the protocol}

The first step is making sense or acquiring a feeling for the protocol. The researcher reviewed the protocols formulated for this study. The researcher transcribed the data obtained from the actual interview and reviewed it several times to ensure consistency of the transcription and what was recorded during the interview. This process was to check that the authenticity of data conveyed was not lost during the transcription. The written transcription of each participant did not contain their names but rather respondents' number for privacy and confidentiality.

\subsubsection{Extracting Significant Statements}

The second step is translating or making the significant statements (SS) out from the written transcription. Taking out or making the significant statements means that the researcher went back to each transcript and took out from the phrases or sentences that directly pertained to the investigated phenomenon (Colaizzi, 1978). The significant statements were placed in the table format to be aligned with the transcription of participants' feelings or thoughts. Each transcription was analyzed after each interview, and the significant statements (SS) were coded or numbered consecutively (e.g., SS1-SS57) for all the participants.

\subsubsection{Formulation of meanings}

After extracting the significant statements (SS) from the transcription, the next step was formulating meanings (FMs) taken from the significant statements. Since the formulation of FMs were intricate, the researcher made sure that he will not deviate from the intended meanings to other meanings not related to the study; therefore, the researcher always checked and verified the significant statements for the accuracy and consistency of the FM. The FMs were also numbered. According to Colaizzi (1978), in determining these formulated meanings, the researcher must ascertain and illuminate the unseen meanings considering the various perspectives and possibilities of the 
phenomenon which is described in the original transcript "and must not formulate meanings which have no connection with the data." To be always guided and stay focused in formulating FMs, the researcher conferred it to her adviser for validation. After all FMs were formulated, the researcher then made the cluster themes out of these formulated meanings.

\subsubsection{Organizing the cluster themes}

The next step was organizing the cluster themes out of the formulated meanings. This was achieved by re-reading the transcript and reviewing the significant statements (SS) and formulated meaning (FM). Consultations were made by the researcher with her adviser regarding the formulated meanings, themes, and the theme clusters.

\subsubsection{Integration of results and Exhaustive description}

Colaizzi's fifth and sixth steps in analyzing incorporated the investigated topic's results into a detailed description and identified its fundamental structure. This was done by combining the theme clusters and themes to make a description. The researcher also reviewed the formulated meanings, significant statements, and the transcription made to ensure completeness of the data transcribed.

\subsubsection{Validation}

Colaizzi's final step of data analysis was the validation of findings. This was done by verifying the clusters as descriptive of their experiences by going back to the participants and asking them to validate the descriptive results' accuracy (detailed description) with their actual results. A copy of the detailed description was given to the participants to read and determine if these were the challenges they encountered in teaching online. All the participants confirmed that what was written in the researcher's exhaustive description was really what they felt and experienced.

\section{Results and Discussion}

This study explored the challenges encountered by the teachers in the implementation of online distance learning. The central themes were derived from analyzing and interpreting the 20 interview script using Colaizzi's (1978) method of data analysis. The researcher first examined the notes from the interview that transpired earlier before transcribing them. A total of 57 significant statements (SS) evolved from the interviews. The researcher interpreted the SS. There were 57 formulated meanings which were coded and categorized into ten themes. The ten themes were reduced to subthemes from which four cluster themes were drawn:

Theme Cluster 1: The Need to Motivate Students in Learning the Lesson.

Theme 1: Keeping students' attention in class

Theme 2: Engaging students for oral participation

Theme 3: Having difficulty in determining if students are learning the lessons.

Theme Cluster 2: Preparation of Learning Resources

Theme 4: Allocating more time in Preparing PowerPoint Presentations for the lessons

Theme 5: Securing updated gadget for an online class

Theme Cluster 3: Poor Internet Connection.

Theme 6: Considering the students' attendance due to poor internet connections

Theme 7: Having difficulty in conducting classes due to unstable internet connections

Theme 8: Designing appropriate activity considering the internet connection.

Theme Cluster 4: Constant Communication with Students and Parents

Theme 9: Making follow-up on students' attendance and performance

Theme 10: Communicating to parents the performance of the students 


\subsection{The Need to Motivate Students in Learning the Lesson}

As the online classes were novel for the students, the teachers' first obstacle was to motivate the students to learn the lesson throughout the online class. It was quite difficult to sustain students' interests because the teachers cannot see the students in person. The teachers cannot also see all of the students' reactions while having the class.

\subsubsection{Keeping students' attention in class}

The teachers felt the challenge in keeping the students' interest during synchronous classes because they cannot even see the students' gestures while the class is ongoing. They could not see whether the students are still connected during the course of the lessons, especially those subjects that need longer hours and those that need computations. As one participant revealed: "It's quite challenging because the teacher needs to keep the students' interest during discussion especially that you can't see them face to face and my lessons are more on calculations that need thorough discussion and analysis" (P1). Besides, some students are also inattentive, especially during synchronous classes. The teacher has to keep student's interest in the activities and monitor if the students are still participating in the discussion. This can be discerned in the answers of participants 2 and 9 stating that: "The struggle on keeping the students attentive during discussion. I let them do interactive activities just to monitor that they are participating" (P2), and "With slow internet connection, students were inattentive during synchronous discussion" (P9).

When it comes to doing some performance activity, Participant 7 also found it difficult to keep them motivated. Some students even got low grades because they did not answer all of the given activities. This was stressed in the statements of participants 7 and 15 that: "It is difficult to maintain motivation to students and also when it comes to teaching performance-based topics." (P7), "Some students got low grades because they didn't answer all the activities given to them." (P15)

While it is true that sustaining students' attention is difficult in online learning, current teaching practices may be improved to satisfy learners' expectations and address the shorter attention spans that are common among today's students. Interest is a strong motivator that energizes learning, directs academic and professional paths, and is critical to academic achievement. Interest is a psychological condition of attention and feeling toward a specific item or topic, as well as a long-term propensity to return to it. Promoting interest can help students have a more engaged and motivated learning experience (Harackiewicz, Smith, \& Priniski, 2016).

\subsubsection{Engaging students for oral participation}

Engagement is a measure of a teachers' ability to motivate students and get involved in online distance learning. This includes interaction and collaboration with the teacher and classmates. In the context of online learning, teachers find difficulty in engaging students in the virtual setting. The participants mentioned that they could not force the students to participate orally in the discussions. These were emphasized by participants 4 and 12 in their remarks: "It is super challenging because you cannot force your students to participate in your discussion" (P4), and "The engagement of students in the learning process because other students are not participating and we could not force them to speak if they don't want to" (P12).

There was also less interaction with the students, and sometimes, the students would even ignore the teachers when they are called to answer and participate. Some students would also put off the camera of their gadgets when they are not responding, students could say they have no internet connection. Teachers would not know what the students are doing while having their class. These were stressed by participants 6 and 11 respectively: "It is fun but really challenging since there's less interaction with students. Some students ignore me when they are called to answer some questions." (P6) and "There is a struggle in the participation of students because we could not see them personally. We do not know what they're doing while we are teaching" (P11). In addition, participant 7 mentioned that "It is kind of hard especially in making students participative in the activities." (P7) and "Persuading our students to participate in the discussion" (P16). In an online class, students' presence is equally important as teachers' presence. Student engagement is a good predictor of a successful learning experience.

Online learning has recently become the norm by work. Students must actively participate in learning to obtain effective learning. Students who participate in online learning, on the downside, do poorly due to a lack of communication between teachers and students, and their tenacity and efficiency are also low ( $\mathrm{Hu}, \& \mathrm{Li}, 2017)$. In other words, engagement may be the most important factor in making online learning a necessary element of higher education and an institution's future (Meyer, 2014). 


\subsubsection{Having difficulty in determining if students are learning the lessons}

In the teaching-learning process, the measure of success in teaching is the students' learning from the lessons. In the online delivery of the lessons, the teachers have more struggles in the subjects they are handling because they cannot correct the assessments immediately and give timely feedback. The teachers cannot even supervise while the students are doing the work. This was the answer of participant 4: "I have struggles in my subject since it's more of the developing the "skills" I really can't supervise them while drawing and correct them during the process" (P4). Students especially in the high school need constant guidance in their work, prodding them to the best and not just be content with mediocrity of their outputs.

Teachers were also not sure if the students are learning or not because they do not say any word. Everyone in the class is extremely quiet that the teachers would not know whether the students were still listening, or if they were learning and if they are having trouble with the lessons taught. This was mentioned by (P5): "The part that I am not used to is the gestures while discussing like students' expressions while you are talking. There you can tell if they're really listening or learning or even having trouble. Even saying "no" or "yes" would give you the clue, but everyone is silent or worse, it takes time to get answers" (P5).

Teachers struggle with their limited resources and with that of the students. It made it hard for them to relay the topics. This is especially true for topics that need solving because they do not have a jamboard that teachers can freely write and demonstrate how to solve a problem. This is the answer of participant 11: "You cannot monitor the students and also some topics cannot be relayed perfectly especially in solving due to limited available resources" (P11). It needed a lot of effort to keep the students understand the lessons. The teachers also have to vary the teaching strategies since students have different learning styles and learning modes. These were emphasized in the answers of participant 12 and 13: "I need to do more online experiences for my students since they have different learning styles and modes." (P12) and "It needs a lot of effort to keep your students focused and understand the discussions" (P13).

Another concern of the teachers that they observed is the activities that the parents or other family members answered. This is a challenge because there is no learning that occurs on the part of the students in this case/scenario. This was revealed in the answer of participant 15: "I also observed that some of the activities given to the students were answered by their parents or members of the family." (P15). Hence, the teachers were now in doubt whether the students understand or not.

The teachers felt a sense of unfulfilled desire to do their best to deliver the lesson when the students do not answer the activities. When students do not care for their studies, and when they seemed not to value the teacher's efforts in teaching the lessons. This was stressed in the answer of participant 17; "It is very hard to teach (especially subjects with numbers involved) and to make students understand by just talking on a mic and only a screen to be seen by the students. You have this constant doubt whether the students understood your lesson or not. I have this feeling of disappointment when students don't do their activities because it's unfulfilling in my part that I have done all my effort and consideration, yet some kids never care for their school life and to effort you gave".

One of the challenges faced by those who work in education is motivating the students to learn. Uninterested or indifferent students, who put up a minimal effort in academic activities, show little interest in improving their level of knowledge or are more concerned with grades and acquiring certificates than with learning itself, are not rare in educational settings, and have been a source of concern for instructors' psychologists. and psychopedagogists (Bzuneck \& Guimaraes as cited by Beluce, \& Oliveira, 2015).

Motivation is important in and of itself, but it is also a significant predictor of learning and achievement. Students who are more motivated learn to stay in class longer, put in more effort, learn more deeply, and perform better on standardized tests. Online learning requires more self-regulation, intrinsic motivation, and independence from the learner than traditional classroom education. Moreover, motivated learners are more likely to undertake challenging activities, be actively engaged, enjoy and adopt a deep approach to learning and exhibit enhanced performance and creativity.

\subsection{Preparation of Learning Resources}

Effective use of proper learning resources helps teachers construct more than superficial knowledge that builds indepth knowledge on a particular subject. Learning resources must be provided to the students to enhance their knowledge and skills on a specified subject. However, in the study, the teachers have greater challenge in preparing instructional materials suited for online learning. They extended more time preparing for PowerPoint presentations for 
the synchronous classes. They need to adjust for the Learning Management System (LMS) used and used updated gadgets that complement with the LMS.

\subsubsection{Allocating more time in preparing PowerPoint presentations for the lessons}

At the onset of online learning as a mode of delivery for instruction, teachers need to re-align their learning materials to make them suitable for digital instruction. One of the challenges teachers encountered was in the amount of time they have to allocate in preparing PowerPoint presentations for all lessons. Not all teachers are used to these technological means of presenting their lessons during the pre-pandemic times. This was mentioned by participants 1 and 3: "At the start, I have to extend more time in preparation for my lessons in PowerPoint" (P1), and "The burden of taking time in making PowerPoint presentations for the students on all lessons" (P3).

Teachers also struggled with preparing modules and the learning materials that go with every module, all in digital means. Participants 12 and 17 found this on: "The preparation of instructional materials because all must be digital" (P12), and "Since it's an online class, you have to prepare every learning material for every module at hand." (P17). With the number of modules to prepare per subject, the teachers have indeed experienced difficulty preparing all the materials needed for the modules before starting classes or while classes are going on. Added to this, they also have to adjust to the new LMS and how to use the learning materials they prepared for the class as mentioned by participant 2: "It's difficult at first, with all the adjustments from learning how to use the LMS, to the presentation of PowerPoint" $(P 2)$.

Teaching in an online learning environment necessitates more preparation than teaching in a traditional classroom did not require technology to be fully utilized. The quality of online learning education may be influenced by how teachers are prepared to teach (Gurley, 2018). A study looked into how teacher education programs could better prepare teachers for teaching in K-12 online learning environments. Findings indicate that teacher education programs should offer field experiences in K-12 online learning environments. That teacher educators must learn, develop, and model the necessary knowledge, skills, and dispositions relevant to K-12 online learning environments (Williams, \& Casale, 2015).

\subsubsection{Securing updated gadgets for online classes}

Equally important as the learning materials used in delivering the lessons are the gadgets used in online classes. The LMS environment dictates that the devices and the applications have to be compatible with the Microsoft 365 for smooth delivery of online classes. This is also one of the problems teachers encountered because they need to updated their gadgets or have to replace them. Some of the participants stressed that: "I need to buy latest specs for laptop" (P1); "I have to sacrifice and buy a new laptop with higher specs which are beyond my budget" (P2); "The use of updated gadget like laptop and the mobile phone that could be used in teaching." (P12); and "Securing gadgets/tech" (P14). This problem is common among the teachers and the students, perhaps because it would be hard for teachers to conduct the online class if students also do not have updated devices that complements that of their teachers. Participant 14 laments that: "If only students have gadgets which have features intended for online classes" (P14). The lessons would go on smoothly and without interruptions.

In addition to the need for devices for teaching and learning, there is the problem of the cost of the gadgets to be used for the online class. With the current situation where costs are continually increasing, it is challenging for the teachers to acquire new or updated versions of their gadgets. This was emphasized by participant 13: "The most common problems that I have encountered in online distance learning include the quality of instruction and cost of using technologies (data connection for laptop, tablet, and cellular phone)" (P13).

Information Communication Technology (ICT) devices play a significant role in many sectors, including education, in today's digital world. These technological devices include, but are not limited to, computers and smartphones connected to the internet (Carver et al. and Alharbi as cited by Bazimaziki, G. (2020). Results of the study of Koirala, Silwal, Gurung, Bhattarai, \& KC (2020) showed that mobile phone was the most commonly (51.9\%) used gadget for attending the online class.

The use of learning devices is very important to promote active learning. With the use of technology in learning, students will acquire skills to analyze, synthesize, thus, develop higher-order thinking skills. It will also help develop their logical reasoning and creative thinking because they allow them to have a more active learning process. 


\subsection{Poor Internet Connection}

Varied accessibility to the internet has compromised the quality of education for students, as most classes are online and rely on high-speed internet connection for synchronous classes. In the study, poor internet connection was considered the main problem for both teachers and students in conducting online classes. If teachers or students fail to connect, classes are jeopardized because there can be no teaching and learning if there are no teachers and students' connections. The internet provides the link in the virtual classroom.

\subsubsection{Considering the students' attendance due to poor internet connections}

Teachers faced difficulties due to weak internet access, which resulted in low student attendance. Internet connections are expected to be disrupted due to the large number of people going online due to the pandemic, and internet connections are expected to be affected. This was one of the challenges that teachers face which is beyond their control. The absence or the poor internet connections greatly affect continuity of lessons and poor attendance of students. Students used internet connectivity as an excuse for their inability to work with their assignments and other activities. These were revealed in the answers of participants: "The adjustments that you have to consider for students especially those who have poor internet connections" (P1); "The challenge is the connections of the internet." (P3); "Students' stability of network connection" (P7); "Slow internet connection" (P8); and "It is not easy because of the internet connection, sometimes only a few students who can join because of the slow internet connection" (P13).

There are numerous ways that a lack of internet access can harm a student's academic performance. Students who do not have access to the internet cannot communicate with teachers or classmates, conduct independent research, or seek online homework assistance. For families, not having access to the internet can mean missing out on important information or losing contact with schools and teachers. Remote working, e-teaching, online collaboration, gaming, video streaming, and other activities have benefited from the Internet (Favale, Soro, Trevisan, Drago, \& Mellia, 2020).

\subsubsection{Having difficulty in conducting classes due to unstable internet connections}

The unstable internet connection is a challenge in the conduct of online classes. Some of the participants stressed this difficulty: "Internet connection is the major problem we, teachers as well as the students, encountered (P2); "Better internet connection not only to teachers but to learners as well" (P4); and "The school's internet connection is the main problem" (P10). Participant 12 also added that they were sometimes disconnected while having their classes. "The stability of internet connection because sometimes we could be disconnected while having our classes" (P12).

According to participant 11, patience is needed from both the teachers and students regarding internet connectivity. "Patience in the connection for both teacher and students" (P11). On the other hand, participant 14 said that she could do nothing on the connection, perhaps because these are already beyond the teacher's and students' control. Some resorted to having asynchronous classes so as not lose time. "We cannot do anything, especially if the internet connection is slow; that's why we also have asynchronous classes” (P14).

Aside from the internet connections problem, participant 7 stressed that the platform itself, which is the Microsoft Teams, also has glitches and malfunctions that hinder, in a way, the conduct of their classes online. "When it comes to the technical aspect, the main thing does not have a stable internet connection. The Microsoft teams also got glitches and malfunctions that became a hindrance to teach smoothly" (P17). This is especially during peak hours when a great majority of classes are on the line. Participant 19 mentioned that his challenge was giving more of their time for remedial lessons, which are usually given towards the end of the cycle to assist the students who have missed classes due to unstable internet connection. "At a teacher's end, by giving a more flexible time for remedial sessions allotting an end-of-cycle schedule/time for learning assistance to those who missed classes due to unstable connection" (P19).

The Internet is increasingly being used inside the classroom (Lenhart, Simon, \& Graziano, 2001). On the other hand, teachers' difficulties are primarily related to technology in the classroom. Educational institutions face the main challenges of providing appropriate instructional technology and effective teacher training support (Rasheed, Kamsin, \& Abdullah, 2020) in the utilization of technological devices in online teaching. 


\subsubsection{Designing appropriate activity considering the internet connection}

Due to poor internet connectivity, the teachers device other means or catch up plans to accomplish the learning objectives as prescribed in the Curriculum Guides from DepEd. They understand the struggles of students trying their best to meet connectivity in designing performance tasks for the requirements and assignments. The teachers could not give the students the exact kind of activity they want the students to do. They have to be flexible at all times even if understandably students make excuses for their failure to meet the requirements. These were supported by the answers of participants 4 and 7: "Availability of the internet connection and the constraint of activities to plan for your class" (P4). and "Giving the students the activities that I want is difficult due to their resources are limited especially when it comes to gadgets and internet connection” (P7).

These disruptions in internet connections may also delay some of the topics. Instead of having synchronous classes, teachers have to back up their lessons with recorded discussions. This was mentioned by participant 10: "I should back my synchronous classes up with recorded class discussion" (P10). This gave them a burden because they have to prepare for both synchronous and asynchronous classes. In some instances, they could not properly implement the module's flow because of interruptions and poor internet connections. This was stressed by participant 20: "The flowin what to do and how could we implement properly the modules being made" (P20).

E-learning experts collaborated on a study to look at the barriers to e-learning adoption and the best strategies for overcoming them. Poor infrastructure, financial constraints, insufficient support, a lack of e-learning knowledge, and teachers' resistance to change were identified as the five major barriers. It is suggested that teachers and administrators receive e-learning training and financial, technical, and managerial support geared toward adoption. Successful elearning adoption necessitates a strategic approach that considers all education stakeholders and factors out barriers (Kisanga \& Ireson, 2015).

Learning materials serve as major learning resources for distance learners, and quality learning materials help students learn effectively at a distance. High-speed Internet connection provided technology significantly reduces the class time allocated by students searching for information and other learning resources and provides them with more chances of synergy for knowledge construction by facilitating browsing, scanning, and searching.

\subsection{Constant Communication with Students and Parents}

In online learning, communication with both parents and students is very important. Since online learning is essentially home-based, the parents act as surrogate teachers who work collaboratively with the teachers. The success of the online learning rests heavily in the hands of the parents and teachers who are the major stakeholders. This requires a regular communication of the students with the parents and inevitably with the teachers. The responses of the teachers revealed the challenges of making follow-up on the students' attendance and performance and communicating to parents the performance of the students.

\subsubsection{Making follow-up on students' attendance and performance}

Making follow-up on students' attendance was one of the challenges faced by the teachers in conducting online classes. They have difficulty in making the students attend the online class. It was observed that in most cases, not all students can attend synchronous classes. This was indicated in the answer of participant 12: "There is a need to strengthen monitoring of students in their attendance in online classes" (P12). Others would say that they could hardly connect, while others do not have enough load.

Constantly follow up on the low-performing students. This was answered by participant 3: "Constant follow-ups need to be done to continuously monitor the low performing students" (P3). Making these follow-ups is a struggle because students have many reasons for their absence and their performance. They would keep on asking for considerations from teachers, yet they are not doing any way to improve their performance. This was also revealed in the answer of participant 2: "Making follow-up to both students and their parents is also a struggle as they always have reasons and always ask for considerations to give them a chance but are not making improvements" (P2). It is indeed quite difficult to follow up the students learning. This was also the answers of the participants 19: "There is difficulty to follow up the students' learning” (P19).

In today's education, school success is defined as ensuring that each student achieves his or her full potential. Student progress monitoring is a method for teachers to use data on student performance to evaluate their teaching 
effectiveness and make more informed instructional decisions (Vilanova et al., 2019). Teachers, according to researchers, must act as agents to introduce and reinforce self-regulation in students' learning experiences (Kramarski, 2018).

\subsubsection{Communicating to parents the performance of the students}

Besides making follow-ups on the students regarding performance and attendance in the class, the teachers also struggle in communicating with the parents to inform them of the progress of their children's performance. This was the concern of participant 1; "There is a need for constant communications and cooperation with parents on their child's learning" (P1). Perhaps, due to the busy schedule of the parents, they could hardly assist their children in their studies. Most of them are also working so they could not be reached by the teachers during office hours. This was the answer of participant 16 and 18: "It was hard to reach out to the parents and keep them updated with the performance of the students" (P16), and "My challenge is informing the parents of their children's performance" (P18).

To support student learning, teachers strove to form partnerships with parents. Maintaining communication is vital between home and school. Teachers continue to develop their skills to maximize effective communication with parents in these changing times. In these changing times, teachers must continue developing and expanding their skills in these changing times (Graham-Clay, 2005).

Parental involvement is increasingly being promoted in educational policies to improve student outcomes (Hamlin \& Flessa, 2018). As a result, families must create a supportive home environment for their children as learners to ensure their children's improved performance in school. It is suggested that both the nurturing and supportive school and home environments should provide successful students (Caño et al., 2016).

For students' success, good two-way communication between families and schools is essential. Teachers may be able to focus more on the task of teaching children if parents are involved. Furthermore, by having more contact with parents, teachers better understand their students' needs and home environments, which they can use to meet those needs better. Parents who are involved tend to have a more positive view of teachers, which improves teacher morale.

\subsection{Exhaustive Description}

The teachers encountered a lot of challenges in the implementation of online distance learning. Among these challenges were the need to motivate the students to learn the lessons, prepare learning resources, the poor internet connection, and constant communication with students and parents.

In motivating the class, the teachers have difficulty keeping the students' attention while having their synchronous classes because they cannot personally see them. They also have a hard time engaging their students; even if the teacher called them for oral recitation, students will still not answer. Hence, teachers also have difficulty in determining whether students learn the lessons or not.

In addition, preparing learning resources for the online class was also a challenge for the students. Spending more time preparing for digital presentations to be used in online discussions is already a burden for the teachers. They have to prepare everything for every lesson because, unlike face to face, they could not demonstrate the lessons presented. Aside from the learning materials preparation, teachers have also to update the gadgets used in online learning. They have to have gadgets with higher specifications to meet the demands of the applications used in online learning.

Poor internet connection was also a big challenge among the teachers and the students. The teachers have to consider the students' attendance because some could not attend synchronous classes due to slow connectivity. Moreover, teachers also have difficulty in conducting synchronous classes because of unstable internet connections. The onset of online activities not only in the field of education makes connectivity unstable for some time. Therefore, teachers were also faced with designing activities for both synchronous and asynchronous classes to back up the lesson delivery in case there would be problems with the internet connections.

Constant communication with the students and parents is very important, especially when teachers could not see them physically. This has also been a challenge for the teachers because they have to call students from time to time to feedback on their performance and monitor their attendance in the class. Besides, they also need to communicate regularly with the parents to be informed of their children's performance. Since teachers could not physically see what the students are doing in the learning process, the parents have a great role in assisting their children in improving their performance. 


\section{Conclusions and Recommendations}

The teachers faced a lot of challenges in the implementation of online distance learning. The researcher concluded that students need more engaging activities to sustain their interest for them to be motivated to learn the lessons. Students need guidance in their work, prodding them to the best and not just settle on the mediocrity of their outputs. Teachers need to allocate more time re-aligning their learning materials to make them suitable for the digital instruction. Upgrading of technological devices is also a must among teachers and students to allow for a smooth delivery of the lessons online. In an online learning environment, connectivity is of much importance both for teachers and students since this provides links in a virtual classroom. Teachers have to understand the unstable connectivity and they need to design lessons for synchronous and asynchronous classes which are essentially home-based. With this, the parents have to act as surrogate teachers who should work collaboratively with the teachers. Therefore, teachers have to constantly communicate with parents to make follow-ups and update them on children's progress.

From these findings and conclusion, the researcher recommends that the administration conduct in-house seminars and trainings on the teaching strategies for online class to sustain their interest in learning; re-alignment outcomes and the assessment activities for it to become engaging and to ensure that the expectations set for the subjects are met; and proper construction of assessment questions that would develop the higher order thinking skills of the students. The administration may also develop mechanisms to aid teachers in acquiring updated gadgets to be used in online teaching. Teachers design back-up plans if internet connectivity will become unstable and may jeopardize the teaching and learning process. Moreover, assistance may also be given to teachers to ease their communication with parents and report students' progress. Various means of reaching out to the students and parents may be explored. Future researchers may also consider conducting another research looking into other factors that challenge the teachers in the implementation of online distance learning.

\section{References}

Alea, L. A., Fabrea, M. F., Roldan, R. D. A., \& Farooqi, A. Z. (2020). Teachers' Covid-19 awareness, distance learning education experiences and perceptions towards institutional readiness and challenges. International Journal of Learning, Teaching and Educational Research, 19(6), 127-144. Retrieved on November 3, 2020 from https://bit.ly/3oW9cGe

Anshari, M., Alas, Y., Sabtu, N. P. H., \& Hamid, M. S. A. (2016). Online Learning: trends, issues and challenges in the Big Data Era. Journal of e-Learning and Knowledge Society, 12(1). Retrieved on November 5, 2020 from https://www.learntechlib.org/p/171433/

Bazimaziki, G. (2020). Challenges in using ICT Gadgets to cope with effects of COVID-19 on Education: A short survey of online teaching Literature in English. Journal of Humanities and Education Development (JHED), 2(4), 299-307. Retrieved on April 16, 2021 from https://bit.ly/3vIzsXa

Beluce, A. C., \& Oliveira, K. L. D. (2015). Students' motivation for learning in virtual learning environments. Paidéia (Ribeirão Preto), 25(60), 105-113. Retrieved on April 18, 2021 from https://www.scielo.br/scielo.php?pid=S0103-863X2015000100105\&script=sci_arttext

Caño, K. J., Cape, M. G., Cardosa, J. M., Miot, C., Pitogo, G. R., Quinio, C. M., \& Merin, J. (2016). Parental involvement on pupils' performance: Epstein's framework. The Online Journal of New Horizons in Education, 6(4), 143-150. $\quad$ Retrieved on $\quad$ April $30, \quad 2021$ from https://www.tojned.net/journals/tojned/volumes/tojned-volume06-i04.pdf\#page=151

Charbonneau-Gowdy, P. (2018). Beyond Stalemate: Seeking Solutions to Challenges in Online and Blended Learning Programs. Electronic Journal of e-Learning, 16(1), 56-66. Retrieved on November 3, 2020 from https://eric.ed.gov/?id=EJ1182388

Favale, T., Soro, F., Trevisan, M., Drago, I., \& Mellia, M. (2020). Campus traffic and e-Learning during COVID-19 pandemic. Computer Networks, 176, 107290. Retrieved on April 16, 2021 from https://www.sciencedirect.com/science/article/abs/pii/S1389128620306046

Gillett-Swan, J. (2017). The challenges of online learning: Supporting and engaging the isolated learner. Journal of Learning Design, 10(1), 20-30. Retrieved on November 5, 2020 from https://eprints.qut.edu.au/102750/ 
Graham-Clay, S. (2005). Communicating with parents: Strategies for teachers. School Community Journal, 15(1), 117-129. Retrieved on April 20, 2021 from https://eric.ed.gov/?id=EJ794819

Gurley, L. E. (2018). Educators' Preparation to Teach, Perceived Teaching Presence, and Perceived Teaching Presence Behaviors in Blended and Online Learning Environments. Online learning, 22(2), 197-220. Retrieved on April 16, 2021 from https://eric.ed.gov/?id=EJ1181399

Hadwin, A. F., Bakhtiar, A., \& Miller, M. (2018). Challenges in online collaboration: Effects of scripting shared task perceptions. International Journal of Computer-Supported Collaborative Learning, 13(3), 301-329. Retrieved on November 2, 2020 from https://link.springer.com/article/10.1007/s11412-018-9279-9

Hamlin, D., \& Flessa, J. (2018). Parental involvement initiatives: An analysis. Educational Policy, 32(5), 697-727. Retrieved on April 20, 2021 from https://journals.sagepub.com/doi/

Harackiewicz, J. M., Smith, J. L., \& Priniski, S. J. (2016). Interest matters: The importance of promoting interest in education. Policy insights from the behavioral and brain sciences, 3(2), 220-227. Retrieved on April 16, 2021 from https://journals.sagepub.com/doi/abs/10.1177/2372732216655542

Hu, M., \& Li, H. (2017, June). Student engagement in online learning: A review. In 2017 International Symposium on Educational Technology (ISET) (pp. 39-43). IEEE. Retrieved on April 16, 2021 from https://www.computer.org/csdl/proceedings-article/iset/2017/08005384/12OmNyQYtr2

Jones, S. H. (2015). Benefits and challenges of online education for clinical social work: Three examples. Clinical Social Work Journal,43(2), 225-235 Retrieved on November 5, 2020 from https://link.springer.com/article/10.1007\%2Fs10615-014-0508-z

Kisanga, D., \& Ireson, G. (2015). Barriers and strategies on adoption of e-learning in Tanzanian higher learning institutions: Lessons for adopters. International Journal of Education and Development using ICT, 11(2). Retrieved on April 18, 2021 from https://www.learntechlib.org/p/151845/

Koirala, D., Silwal, M., Gurung, S., Bhattarai, M., \& KC, V. K. (2020). Perception towards online classes durin g COVID-19 among nursing students of a medical college of Kaski District, Nepal. Journal of Biomedical Research \& Environmental Sciences, 1(6), 249-255. Retrieved on March 25, 2021 from https://www.jelsciences.com/articles/jbres1151.pdf

Kramarski, B. (2018). Teachers as agents in promoting students' SRL and performance: Applications for teachers dual-role training program. Retrieved on April20, 2021 from https://psycnet.apa.org/record/2017-45259-015

Lenhart, A., Simon, M., \& Graziano, M. (2001). The Internet and Education: Findings of the Pew Internet \& American Life Project. Retrieved on April 16, 2021 from https://eric.ed.gov/?id=ED457849

Meyer, K. A. (2014). Student engagement in online learning: What works and why. ASHE higher education $\begin{array}{llllll}\text { report, 40(6), } & \text { 1-114. } & \text { Retrieved } & \text { on } & \text { March }\end{array}$ fromhttps://psychology.usu.edu/research/factotum/files/Student\%20Engagement\%20in\%20Online\%20Learn ing $\% 20-\% 20$ What $\% 20$ Works $\% 20$ and $\% 20$ Why.pdf

Muhtia, A., Suparno, S., \& Sumardi, S. (2018, July). Blended learning using schoology as an online learning platform: Potentials and challenges. In English Language and Literature International Conference (ELLiC) Proceedings (Vol. 2, pp. 171-175). Retrieved on November 4, 2020 from https://jurnal.unimus.ac.id/index.php/ELLIC/article/view/3531

Nguyen, T. (2015). The effectiveness of online learning: Beyond no significant difference and future horizons. MERLOT Journal of Online Learning and Teaching, 11(2), 309-319. Retrieved on November 2, 2020 from https://jolt.merlot.org/Vol11 no2/Nguyen_0615.pdf

Rajab, M. H., Gazal, A. M., \& Alkattan, K. (2020). Challenges to online medical education during the COVID-19 $\begin{array}{llllll}\text { pandemic. Cureus, } 12(7) . & \text { Retrieved on } & \text { November } & 5, & 2020 & \text { from }\end{array}$ https://www.ncbi.nlm.nih.gov/pmc/articles/PMC7398724/

Ramli, M. F., Majid, M., \& Badyalina, B. (2020). Impeding Factors Towards the Effectiveness of Online Learning During Covid-19 Pandemic among Social Sciences Students. International Journal of Learning and Development, 10(4), 37. Retrieved on March 25, 2021 from https://bit.ly/33JsaGG 
Rasheed, R. A., Kamsin, A., \& Abdullah, N. A. (2020). Challenges in the online component of blended learning: A systematic review. Computers \& Education, 144, 103701. Retrieved on March 25, 2021 from https://www.sciencedirect.com/science/article/abs/pii/S0360131519302544

Rasheed, R. A., Kamsin, A., \& Abdullah, N. A. (2020). Challenges in the online component of blended learning: A systematic review. Computers \& Education, 144, 103701. Retrieved on November 5, 2020 from https://www.sciencedirect.com/science/article/abs/pii/S0360131519302544

Tarus, J. K., Gichoya, D., \& Muumbo, A. (2015). Challenges of implementing e-learning in Kenya: A case of Kenyan public universities. International review of research in open and distributed learning, 16(1), 120-141. Retrieved on November 4, 2020 from https://www.erudit.org/en/journals/irrodl/1900-v1-n1irrod104978/1065931 ar/abstract/

Toquero, C. M. (2020). Challenges and Opportunities for Higher Education Amid the COVID-19 Pandemic: The Philippine Context. Pedagogical Research, 5(4). Retrieved on November 5, 2020 from https://eric.ed.gov/?id=EJ1263557

Tria, J. Z. (2020). The COVID-19 Pandemic through the lens of education in the Philippines: The New Normal. International Journal of Pedagogical Development and Lifelong Learning, 1(1), 2-4. Retrieved on November 3, 2020 from https://bit.ly/3oU5xc1

Vilanova, R., Dominguez, M., Vicario, J., Prada, M. A., Barbu, M., Varanda, M. J.,\& Paganoni, A. (2019). Datadriven tool for monitoring of students performance. IFAC-PapersOnLine, 52(9), 16 5-170. Retrieved on March 25, 2021 from https://www.sciencedirect.com/science/article/pii/S2405896319305257

Williams, N. V., \& Casale, M. J. (2015). The Preparation of Teacher Candidates for K-12 Online Learning Environments: A Case Study. Mid-Western Educational Researcher, 27(2). Retrieved on March 25, 2021 from https://bit.ly/3trJM4y 